\title{
An impact Assessment of Watershed Projects in Tribal Districts of Odisha
}

\author{
Shishira Kanta Behera* \\ Institute of Agricultural Sciences, SOA deemed to be University, Odisha, India \\ *Corresponding author
}

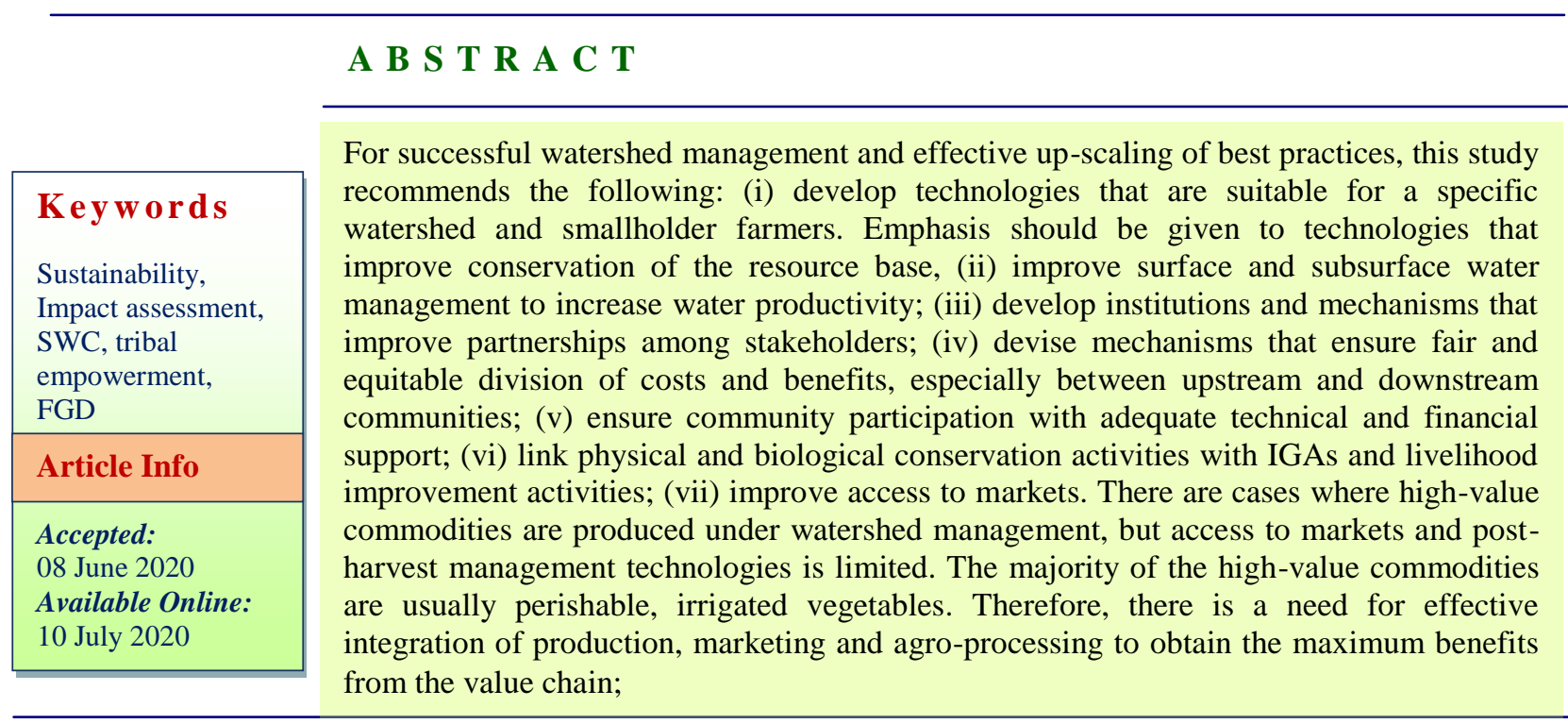

\section{Introduction}

Agriculture is the main sector of the Odisha economy and contributes approximately $42 \%$ to the gross domestic product (GDP) and employs over $80 \%$ of the population. Despite its role, agricultural production is constrained by high climate variability where rainfall distribution is extremely uneven and this has negative implications for the livelihoods of people .Drought frequently results in crop failure, while high rainfall intensities result in low infiltration and high runoff causing enhanced soil erosion and land degradation.
Land degradation in the form of soil erosion and declining land fertility is a serious challenge to agricultural productivity and economic growth (Lemenih 2004).

Studies indicate that the tribal district of Odisha have experienced high rates of soil erosion and deforestation, resulting in sediment accumulation in downstream reservoirs and rivers. In general, watershed degradation resulted in long-term reduction in the quantity and quality of water and land resources, which negatively impact on the livelihoods of the rural poor. 
This spurred the Odisha government to launch an extensive soil and water conservation (SWC) program, which began in the early 1970s. In response to the frequent drought in the northern and western part of the State during the period in every four years the World Food Programme (WFP) supported the Food for Work (FFW) project, which was launched in 1974 initially as an emergency relief initiative. This project later evolved into a development.

The participatory integrated watershed management approach emphasizes improving the productivity of water and land resources in an ecologically and institutionally sustainable way (Farrington et al., 1999). Hence, watershed management has become a central point of the rural development and poverty alleviation agenda. According to the participatory watershed management guidelines (L. Desta et al., 2005), the objective of watershed management is to improve the livelihoods of rural communities and households through

SWC for productive uses;

rainwater harvesting for improved groundwater recharge;

promoting sustainable farming systems and agricultural productivity adopting suitable soil, water, nutrient and crop management practices;

rehabilitating and reclaiming marginal lands through appropriate conservation measures, such as planting of trees, shrubs and grasses depending on existing potential;

enhancing the income of smallholders by diversifying agricultural practices and income -generating activities (IGAs).

\section{Project area}

The State of Odisha endowed with rich natural resources, is also one of the poorest states. The Schedule Tribes (ST) and Schedule Castes (SC) constitute nearly $40 \%$ of the population of Odisha. There are 62 Tribal groups and 13 particularly vulnerable Tribal groups (PVTGs) living in the state, a majority of whom are economically, politically and socially backward. In spite of several interventions by both the State and Central Governments, the Tribal communities are far behind the so called mainstream of development.

Focusing on the STs, the Government of India and State Government jointly sought assistance of IFAD for its financial support for the holistic development of the Tribal communities in the state. The Project was implemented in 30 backwards blocks of seven districts Kalahandi, Kandhamal, Koraput, Gajapati, Nabarangpur, Malkanagiri and Rayagada of Odisha in 358 micro watersheds covering and treating an area of 175,358 hectors. The target households include $75 \%$ of ST, $14 \%$ of SC and $11 \%$ of other communities along with $70 \%$ BPL house hold.

Odisha Tribal Empowerment and Livelihood Project was implemented in 30 Blocks of seven districts by the respective Integrated Tribal Development Agencies (ITDAs) in the south-western region of Odisha covering 56180 households in 358 micro-watersheds and 1042 villages. These Blocks have high concentration of tribal households. Poverty rate of these Tribal communities at baseline was $63 \%$.The project area is in remote locations devoid of critical infrastructure such as road network, water supply, markets, credit, etc.. Major parts of the programme areas in the southern tribal belt are plateaus at altitudes ranging between 800 and $1000 \mathrm{~m}$. Large variations in hydrology and vegetation within short distances create a mosaic of extremely diverse environment. A characteristic climatic feature of the area is that its proneness to drought, due not so much 
to a scarcity of rainfall (the area receives 1040-1400 mm of rainfall per annum) but its extreme unreliability. Dry spell of 15-25 days can destroy crops during the main cropping season of June to October. Nearly $76 \%$ of farmers are small farmers cultivating less than 2 ha of land and over $50 \%$ of farmers have less than 1 ha of land. Landlessness is high (20-30\% households with absolute landlessness; over 50\% landless households as per definition of the state government) but a sizable number of them are engaged in share cropping. Agricultural productivity is low with an average productivity of 350 to 450 $\mathrm{kg} / \mathrm{ha}$ of rice, one of the major crops of the project area.

Access to land is the key defining factor in vulnerability to poverty. On average, agriculture provided households with sufficient food for a maximum of six months in any normal year whilst those households that relied on shifting cultivation (podu) their production covered barely one to two months. The reason for seasonal food shortage was mainly due to low productivity of land. Ecological imbalance has been seriously undermining the livelihood patterns of tribal households and increasing their vulnerability. Shifting cultivation has also been leading to severe soil erosion, loss of soil fertility and declining productivity of crops. With their increased dependence on land and agriculture, lack of title to land and the related potential for dispute was a major source of tension in the tribal area.

\section{Materials and Methods}

The Study adopted a quasi-experimental design along with a mixed approach of combining quantitative and qualitative methods viz. household survey, focused group discussions interviews with key stakeholders and assessment of physical interventions .Multistage random sampling was adopted for selection 2017 households and the data collected from the respondents were by using CAPI (Computer assisted Personal Interviewing)tools. The members of the experts team visited selected villages and had interactions with individual beneficiaries,groups ,projects-supported village-institutions, the staff of the FNGOs and the ITDA and other government departments. Findings are presented in terms of achievements against agreed projects (output, outcome) and standard development indicators and on analysis of project management and normative concerns. Establishment of theory of change by comparing with baseline and control and causality attribution have also been made

\section{Results and Discussion}

The key findings of the impact assessment in different sectors like land and water management, agriculture practices, productivity, yield and income are,

Treated about 175,368 ha of land in 358 micro watersheds.

$86 \%$ of households are directly benefitted.

There has been $22 \%$ increase in arable land and $8 \%$ increase in irrigation area.

ORSAC analysis indicates about $34 \%$ reduction in fallow land.

$54 \%$ rate of the structures are satisfactory.

In case of adoption of improved agricultural practices,

These interventions have benefitted over $81 \%$ of the targeted households.

$77 \%$ of the farmers are using such technology.

Double cropping area has increased by $54 \%$ as per ORSAC analysis.

Farm income has increased from Rs4756/ in the year 2005 to Rs.9785/ during 2017.

Farmers productivity has increased from 
$0.69 \mathrm{t} /$ ha to $0.79 \mathrm{t} / \mathrm{ha} .37 \%$ of households attribute yield enhancement to adaptation of practices recommended.

Cropping intensity has increased by $2.7 \%$ against $5.4 \%$ decrease in the State for the same period.

Crop diversification index is 0.67 which is higher than the state average of 0.52 .

Double cropping has increased by $50 \%$ with summer crop area increasing to almost three times.

There is enhanced soil fertility and organic carbon stocks in the project area than the control.

Quality of life, a composite index of access to clean and safe drinking water, access to clean fuel, use of toilet, electricity connection and malnutrition, shows better quality of life in the project area marginally over the control areas.

\section{Participation in land \& water Management Measures}

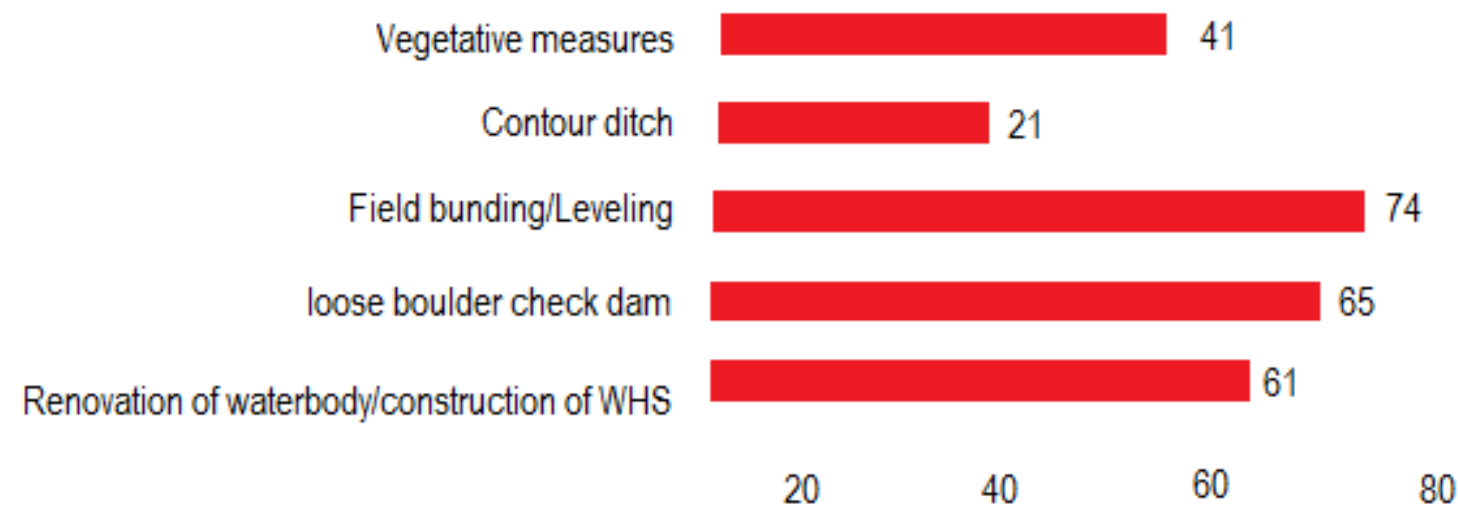

Fig.1 Participation in land \& water management measures

\section{Adoption of Improved agricultural Practices}

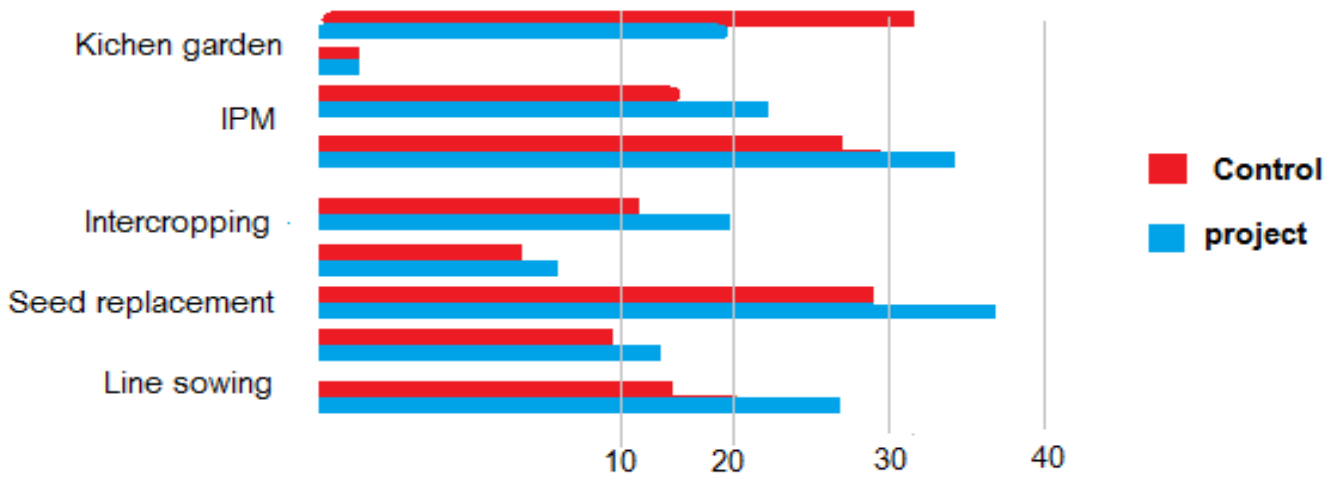

Fig. $2 \%$ of households adopted 


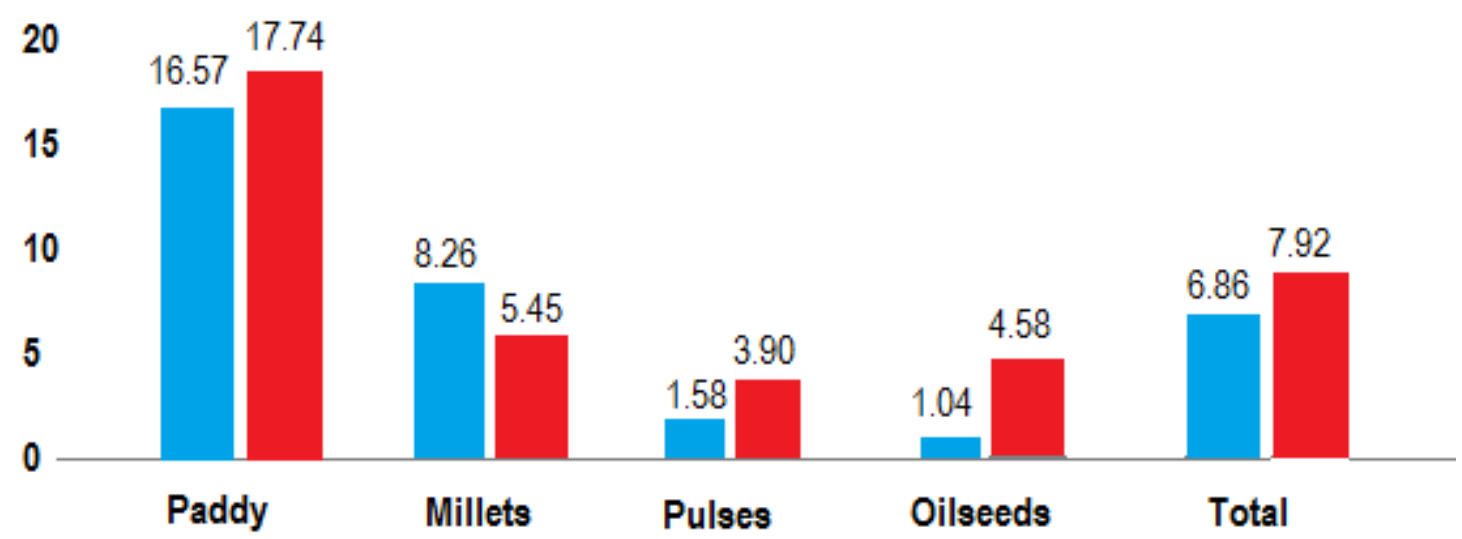

Fig.3 Average crop yield per ha in quintal

For successful watershed management and effective up-scaling of best practices, this study recommends the following:

Develop technologies that are suitable for a specific watershed and small holder farmers. Emphasis should be given to technologies that improve conservation of the resource base, while eliciting short-term benefits for the local people;

Improve surface and subsurface water management to increase water productivity;

Develop institutions and mechanismsthat improve partnerships among stakeholders;

Devise mechanisms that ensure fair and equitable division of costs and benefits, especially between upstream and downstream communities;

Ensure community participation with adequate technical and financial support;

Link physical and biological conservation activities with IGAs and livelihood improvement activities;

Improve access to markets.

There are cases where high-value commodities are produced under watershed management, but access to markets and postharvest management technologies is limited. The majority of the high-value commodities are usually perishable, irrigated vegetables. Therefore, there is a need for effective integration of production, marketing and agro-processing to obtain the maximum benefits from the value chain.

\section{References}

Annual report of OTELP, 20014,2015,20161nd,2017, Govt. of Odisha

Asefa, D.T., Oba, G., Weladji, R.B.,Colman, J.E. 2003. An assessment of restoration of biodiversity in degraded high mountain grazing lands in northern Ethiopia. Land Degradation \& Development 14(1): 25-38.

ATA (Ethiopian Agricultural Transformation Agency). 2013. Annual report 2013/2014: Transforming agriculture in Ethiopia. Addis Ababa, Ethiopia: Ethiopian Agricultural Transformation Agency (ATA)..

Desta, G., Nyssen, J., Poesen, J.Deckers, J.,Mitiku, H.,Govers, G.; Moeyersons, J. 2005. Effectiveness of stone bunds in controlling soil erosion on cropland in the Tigray Highlands, northern Ethiopia. Soil Use and Management 21(3): 287-297.

Desta, L.; Carucci, V.; Wendem-Ageňehu, A.Abebe, Y. (Eds). 2005. Community based participatory watershed 
development: A guideline. Addis Ababa, Ethiopia: Ministry of Agriculture and Rural Development (MoARD).

Farrington, J, Turton, C, James, A.J 1999, Participatory Watershed Development: Challenges for Twenty first Century., Oxford University Press, New Delhi, India.
Murty,V,V,N.Jha,M.K.2013, Land and Water Management Engineering, Sixth edition, Kalyani Publishers, New Delhi. Ramakrishna, P.S, 2004, Ecology and Sustainable Development, $2^{\text {nd }}$ edition, National Book Trust of India

\section{How to cite this article:}

Shishira Kanta Behera. 2020. An impact Assessment of Watershed Projects in Tribal Districts of Odisha. Int.J.Curr.Microbiol.App.Sci. 9(07): 747-752.

doi: https://doi.org/10.20546/ijcmas.2020.907.086 